Quim. Nova, Vol. 33, No. 4, 904-908, 2010

\title{
COMPARAÇÃO ENTRE PROCESSOS EM SHF E EM SSF DE BAGAÇO DE CANA-DE-AÇÚCAR PARA A PRODUÇÃO DE ETANOL POR Saccharomyces cerevisiae
}

\author{
Julliana Ribeiro Alves dos Santos, Ana Maria Souto-Maior e Ester Ribeiro Gouveia* \\ Departamento de Antibióticos, Universidade Federal de Pernambuco, 50670-901 Recife - PE, Brasil \\ Carlos Martín \\ Departamento de Química e Ingeniería Química, Universidad de Matanzas, 44740 Matanzas, Cuba
}

Recebido em 12/8/09; aceito em 24/11/09; publicado na web em 10/3/10

\begin{abstract}
COMPARISON OF SHF AND SSF PROCESSES FROM SUGAR CANE BAGASSE FOR ETHANOL PRODUCTION BY
Saccharomyces cerevisiae. In this work, four different process configurations, including three simultaneous saccharification and fermentation (SSF) schemes and one separate hydrolysis and fermentation (SHF) scheme, were compared, at 8\% water-insoluble solids, regarding ethanol production from steam-pretreated and alkali-delignified sugar cane bagasse. Two configurations included a $16 \mathrm{~h} \mathrm{lasting}$ enzymatic presaccharification prior to SSF, and the third one was a classical SSF without presaccharification. Cellulose conversion was higher for the delignified bagasse, and higher in SSF experiments than in SHF. The highest cellulose-to-ethanol conversion (around $60 \%$ in $24 \mathrm{~h})$ and maximum ethanol volumetric productivities $(0.29-0.30 \mathrm{~g} / \mathrm{L} . \mathrm{h})$ were achieved in the presaccharification-assisted SSF.
\end{abstract}

Keywords: bagasse; hydrolysis; fermentation.

\section{INTRODUÇÃO}

Materiais lignocelulósicos, como o bagaço de cana-de-açúcar, são os mais abundantes complexos orgânicos de carbono na forma de biomassa de planta e consistem principalmente de três componentes: celulose, hemicelulose e lignina. ${ }^{1}$ A utilização de resíduos agroindustriais, como o bagaço de cana-de-açúcar, tem aumentado em processos como, geração de eletricidade, produção de polpa e papel e produtos de fermentação, como etanol e enzimas. ${ }^{2}$ A produção de etanol celulósico, a partir do bagaço de cana-de-açúcar, requer a hidrólise da celulose, que pode, após pré-tratamento, ser realizada por celulases e $\beta$-glucosidase. ${ }^{3,4}$

O pré-tratamento do bagaço com o uso de vapor tem sido apresentado como uma alternativa para melhorar sua digestibilidade, uma vez que ocorre a solubilização parcial e/ou degradação da hemicelulose e da lignina. ${ }^{5}$ A hemicelulose forma uma barreira física ao redor da celulose, mas o pré-tratamento a vapor hidrolisa parcialmente a hemicelulose. A lignina também forma uma barreira física que bloqueia o ataque de enzimas, mas, infelizmente, não é extensivamente removida pelo tratamento a vapor. ${ }^{6}$

Após o pré-tratamento do material lignocelulósico, as próximas etapas para a obtenção de etanol são a hidrólise enzimática e a fermentação que podem ocorrer em separado ou simultaneamente. ${ }^{7}$ A vantagem do processo em separado (SHF) é que as temperaturas da hidrólise enzimática e da fermentação podem ser otimizadas. ${ }^{8}$ A hidrólise enzimática é realizada por celulases (endoglucanase e exoglucanase), que quebram a celulose em celobiose, e esta é, subsequentemente, convertida em duas moléculas de glicose pela $\beta$-glucosidase. ${ }^{9}$

Entretanto, a atividade da endoglucanase é inibida pela celobiose e a da $\beta$-glucosidase pela glicose. ${ }^{10} \mathrm{~A}$ sacarificação e fermentação simultâneas (SSF) é uma forma de evitar a inibição enzimática, uma vez que à medida que a glicose está sendo formada, também está sendo consumida para a produção de etanol, levando a uma maior conversão de celulose. ${ }^{11}$

Um processo em SSF requer uma condição intermediária de temperatura para as enzimas e para a levedura adicionada, uma vez que a temperatura ótima para a sacarificação é cerca de $55^{\circ} \mathrm{C}$ e $30^{\circ} \mathrm{C}$ para a fermentação. ${ }^{11} \mathrm{~A}$ agitação também é outra variável que requer

\footnotetext{
*e-mail: estergouveia@gmail.com
}

uma condição intermediária. Saccharomyces cerevisiae é o microorganismo utilizado no Brasil para a produção de etanol. Entretanto, este micro-organismo converte satisfatoriamente glicose em etanol e $\mathrm{CO}_{2}$ apenas em condições de anaerobiose. ${ }^{12}$ Por outro lado, a sacarificação é realizada, geralmente, a $150 \mathrm{rpm} .^{13}$

O objetivo deste trabalho, portanto, foi comparar dois tipos de processos para a produção de etanol, isto é, fermentação e sacarificação realizadas simultânea e separadamente, a partir de bagaço de cana-deaçúcar. O bagaço utilizado foi pré-tratado com vapor e dividido em dois lotes, um dos quais foi submetido à deslignificação alcalina e o outro não foi deslignificado. Os dois lotes foram sacarificados enzimaticamente e os hidrolisados obtidos foram fermentados por $S$. cerevisiae num proceso SHF. Numa segunda etapa, foram realizadas sacarificação e fermentação simultaneamente, utilizando apenas o bagaço tratado com vapor e deslignificado, com experimentos com e sem etapa de pré-sacarificação, adicionando-se as enzimas de uma única vez ou em duas etapas, isto é, no início e após o período de pré-sacarificação.

\section{PARTE EXPERIMENTAL}

\section{Bagaço de cana-de-açúcar}

Foram utilizados bagaços pré-tratados com vapor na Usina Vale do Rosário (SP), gentilmente cedidos pela Escola de Engenharia de Lorena (USP), deslignificados ou não. O pré-tratamento do bagaço, com uma umidade de aproximadamente $50 \%$, foi realizado em reator de $5000 \mathrm{~L}$ a uma pressão de $15,3 \mathrm{kgf} / \mathrm{cm}^{2}$ (equivalente a $200{ }^{\circ} \mathrm{C}-$ pressão de vapor d'água), durante $7 \mathrm{~min}$. A completa abertura da válvula da base do reator se deu em $15 \mathrm{~s}$ e o material pré-tratado foi transferido para um ciclone por diferença de pressão. O material foi lavado exaustivamente até a total remoção dos açúcares hidrolisados e, em seguida, foi seco à temperatura ambiente e armazenado.

\section{Deslignificação}

O processo de deslignificação foi realizado em reator do tipo autoclave eletrônica, modelo: AU/E-20, do fabricante Regmed Indústria Técnica de Precisão Ltda. Foram transferidos para o reator, $0,5 \mathrm{~kg}$ 
de bagaço pré-tratado com vapor, $10 \mathrm{~L}$ de água destilada e $100 \mathrm{~g}$ de $\mathrm{NaOH}$. A mistura permaneceu à $100{ }^{\circ} \mathrm{C}$, durante $1 \mathrm{~h}$, sob agitação de 100 rpm. Após a deslignificação, a polpa foi separada do licor por filtração. A polpa foi submetida a 7 lavagens, cada uma com $2,5 \mathrm{~L}$ de água destilada, fervente, para a retirada da lignina que ainda estava impregnada no material. ${ }^{14}$ A caracterização quanto aos teores de celulose, hemicelulose e lignina foi realizada segundo metodologia validada por Gouveia et al. ${ }^{15} \mathrm{O}$ bagaço não deslignificado continha (em \%): celulose $(49,89)$, hemicelulose $(7,99)$ e lignina $(34,49)$; por outro lado, o bagaço deslignificado continha (em \%): celulose $(84,20)$, hemicelulose $(3,81)$ e lignina $(10,05)$.

\section{Hidrólises enzimáticas dos bagaços de cana-de-açúcar}

Todas as hidrólises foram realizadas em frascos de Erlenmeyer de $500 \mathrm{~mL}$ com: $8 \mathrm{~g}$ de bagaço, $100 \mathrm{~mL}$ de tampão citrato de sódio $(\mathrm{pH}=4,8)$ e preparações comerciais de celulases e $\beta$-glucosidases (Novozymes A/S, Bagsværd, Dinamarca). A carga de enzimas foi de $30 \mathrm{FPU} / \mathrm{g}$ bagaço e $20 \mathrm{CBU} / \mathrm{g}$ bagaço.

Os frascos, em todas as hidrólises enzimáticas, foram mantidos em mesa incubadora rotativa (New Brunswick Scientific Incubator Shaker $\mathrm{C} 25 \mathrm{KC}$ ), a $50{ }^{\circ} \mathrm{C}$ e $150 \mathrm{rpm}$. Todas as amostras foram centrifugadas (Eppendorf, Minispin) por 15 min na rotação de 10.000 rpm, sendo os sobrenadantes, após filtração em membrana de 0,45 $\mu \mathrm{m}$, utilizados para a quantificação de carboidratos por cromatografia liquida de alta eficiência.

\section{Micro-organismo e meios de cultura}

O micro-organismo utilizado nas fermentações foi uma linhagem industrial de Saccharomyces cerevisiae (UFPEDA 1238), cedida pela Coleção de Culturas do Departamento de Antibióticos da Universidade Federal de Pernambuco. O meio de cultura utilizado para a conservação do micro-organismo foi o meio GLP, em tubo de ensaio inclinado, composto de (em g/L): glicose (20), extrato de levedura (5), peptona (3) e ágar (15). $\mathrm{O}$ pH deste meio foi ajustado para 7,0. Na preparação do inóculo, também foi utilizado o meio GLP, porém sem adição de ágar. $\mathrm{O}$ meio de fermentação continha (em g/L): $\left(\mathrm{NH}_{4}\right)_{2} \mathrm{SO}_{4}(1), \mathrm{K}_{2} \mathrm{HPO}_{4}(0,5), \mathrm{MgSO}_{4} .7 \mathrm{H}_{2} \mathrm{O}(0,25)$, extrato de levedura (2) e peptona (1). Nas fermentações após as hidrólises, o $\mathrm{pH}$ do meio de fermentação foi ajustado para 5,0. Nas fermentações e sacarificações simultâneas, o meio de fermentação foi preparado tendo os seus componentes dissolvidos em tampão de citrato de sódio com pH igual a 4,8 .

\section{Preparo do inóculo}

Na preparação do inóculo, a linhagem foi repicada em tubo de ensaio contendo o meio GLP sólido com pH igual a 7,0, o qual foi mantido a $30{ }^{\circ} \mathrm{C}$ durante $24 \mathrm{~h}$. Após esse período, o inóculo foi preparado através de outro repique em frasco de Erlenmeyer de 250 $\mathrm{mL}$ contendo $50 \mathrm{~mL}$ de meio GLP líquido, o qual foi acondicionado a $250 \mathrm{rpm}$ e a $30^{\circ} \mathrm{C}$, durante $12 \mathrm{~h}$.

\section{Fermentações}

As fermentações utilizando os hidrolisados enzimáticos foram realizadas em estufa a $30^{\circ} \mathrm{C}$. Foram utilizados frascos de Erlenmeyers de $250 \mathrm{~mL}$, contendo $90 \mathrm{~mL}$ de meio de fermentação e $10 \mathrm{~mL}$ do inóculo, após filtração das células em membrana de 0,45 $\mu \mathrm{m}$. Estas fermentações foram realizadas durante $48 \mathrm{~h}$.

Nas fermentações dos experimentos em SSF, após filtração do inóculo, foi realizada uma diluição em meio de fermentação para a obtenção de uma concentração de $1 \mathrm{~g} / \mathrm{L}$. Assim como nas fermentações em SHF, um volume de $10 \mathrm{~mL}$ da suspensão no meio de fermentação foi transferido para cada um dos frascos de Erlenmeyers de $250 \mathrm{~mL}$ contendo $90 \mathrm{~mL}$ do hidrolisado enzimático após o período de pré-sacarificação.

Foram realizados três ensaios de fermentação e sacarificação simultâneas em frascos de Erlenmeyer de $250 \mathrm{~mL}$, com $90 \mathrm{~mL}$ de volume útil, composto de bagaço; enzimas e o meio de fermentação preparado com o tampão citrato de sódio. Em dois dos experimentos (1 e 2) houve uma etapa de pré-sacarificação a $50^{\circ} \mathrm{C}$ e $150 \mathrm{rpm}$, durante $16 \mathrm{~h}$. Após este período, foi iniciada a sacarificação e fermentação simultâneas ao se adicionar o inóculo contendo a levedura numa concentração de 1 $\mathrm{g} / \mathrm{L}$. Esta etapa foi realizada a $32^{\circ} \mathrm{C}$ e $100 \mathrm{rpm}$, durante $72 \mathrm{~h}$.

Nos três experimentos, foi utilizado bagaço de cana-de-açúcar a $8 \% \mathrm{~m} / \mathrm{v}$, pré-tratado com vapor e deslignificado. Nos dois ensaios que tiveram uma etapa de pré-sacarificação, as enzimas (celulases e $\beta$-glucosidase) foram adicionadas numa única etapa, ou seja, no início (experimento 2), ou em duas etapas, isto é, 2/5 de celulases (Celluclast - 21 FPU/g bagaço) no início e 3/5, junto com a adição da levedura (experimento 1). A carga enzimática de celulases foi igual àquela utilizada por Martín et al.. ${ }^{11}$ A quantidade de $\beta$-glucosidase (Novozym 188) adicionada correspondeu a $1 / 5$ (116,7 CBU/mL) do volume utilizado de Celluclast. O experimento 3 foi realizado sem a etapa de pré-sacarificação, isto é, este experimento teve início com a adição do bagaço, do meio de fermentação preparado em tampão citrato de sódio, do inóculo diluído no meio de fermentação (1 g/L) e das enzimas.

A conversão enzimática da celulose (ECC) durante as sacarificações e fermentações simultâneas foi calculada utilizando-se a concentração final de etanol e a concentração residual de celulose: ${ }^{16}$

$$
E C C=\frac{C_{\text {final }_{E t O H}}}{C_{\text {residual Celulose }} * 0,57}
$$

A concentração residual de celulose foi calculada em cada tempo, considerando-se o que já tinha sido convertido durante o período de pré-sacarificação, para os experimentos 1 e 2 . O fator 0,57 é o rendimento estequiométrico de etanol a partir da celulose.

\section{Métodos analíticos}

Para a construção das curvas de calibração dos carboidratos, foram injetadas, em cromatógrafo líquido de alta eficiência (Agilent 1100), soluções contendo celobiose, glicose e xilose. As condições das análises foram: ${ }^{15}$ coluna Phenomenex Rezex ROA-Organic Acid $\mathrm{H}^{+}(8 \% \mathrm{~V} / \mathrm{V})$; fase móvel: $\mathrm{H}_{2} \mathrm{SO}_{4} 0,005 \mathrm{~mol} / \mathrm{L}$; fluxo de $0,6 \mathrm{~mL} / \mathrm{min}$; temperatura do forno de $45^{\circ} \mathrm{C}$ e detector de índice de refração. $\mathrm{Na}$ determinação de etanol, foram injetadas soluções padrão em diferentes concentrações para a construção da curva de calibração. Foram modificadas apenas a temperatura para $30^{\circ} \mathrm{C}$ e a vazão para $1 \mathrm{~mL} / \mathrm{min}$. Todos os experimentos foram realizados em duplicata e o coeficiente de variação foi menor que 5\% para todos os casos.

\section{RESULTADOS E DISCUSSÃO}

\section{Hidrólises enzimáticas}

As hidrólises dos bagaços com e sem deslignificação foram realizadas durante 72 h, como apresentado na Figura 1, para os perfis dos carboidratos. A partir de $10 \mathrm{~h}$, as concentrações de glicose, celobiose e xilose praticamente se mantiveram constantes, na hidrólise do bagaço não deslignificado. Para o bagaço deslignificado, houve formação de glicose até 48 h, quando, a partir desse momento, a concentração de glicose também se mantém praticamente constante. 


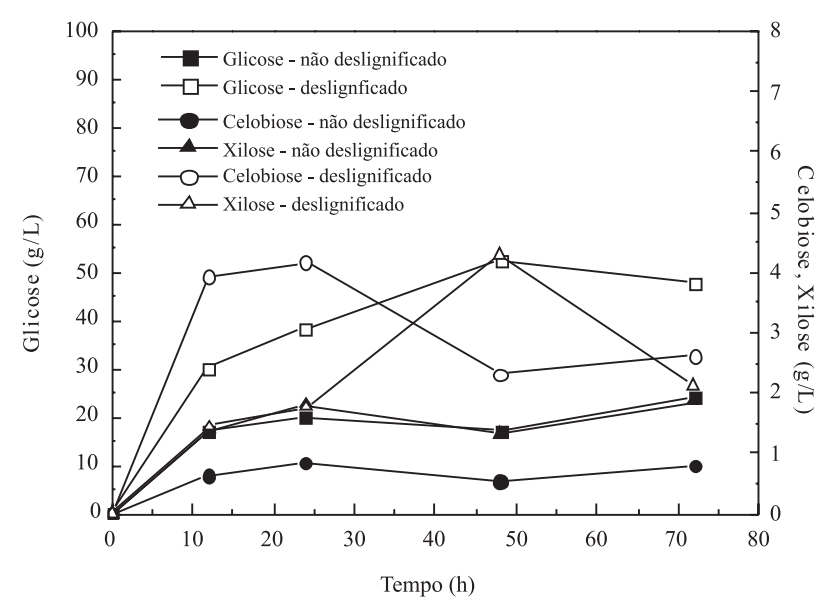

Figura 1. Concentração de glicose, de celobiose e de xilose durante as hidrólises enzimáticas dos bagaços com e sem deslignificação

A concentração de celobiose na hidrólise do bagaço deslignificado aumentou durante as primeiras $10 \mathrm{~h}$, manteve-se constante até $24 \mathrm{~h}$ e depois diminuiu, mostrando a ação da $\beta$-glucosidase. Entretanto, provavelmente a quantidade de $\beta$-glucosidase não foi suficiente, pois permaneceu certa quantidade de celobiose sem ser hidrolisada, bem maior que aquela observada para o bagaço não deslignificado. A quantidade de celobiose formada no bagaço deslignificado é maior do que aquela vinda do bagaço não deslignificado, uma vez que o bagaço deslignificado contém um maior teor de celulose. ${ }^{14}$ Chen et al. ${ }^{17}$ também observaram um acúmulo de celobiose durante a hidrólise enzimática de sabugo de milho, quando não utilizaram uma quantidade suficiente de $\beta$-glucosidase. A concentração de xilose sofreu um pequeno aumento, provavelmente devido à ação de enzimas xilanolíticas sobre oligômeros solúveis. ${ }^{14}$

A quantidade de glicose formada quando se utilizou o bagaço deslignificado foi cerca de duas vezes maior que a quantidade de glicose formada com o bagaço não deslignificado, o que refletiu na conversão enzimática da hidrólise (Figura 2). Vale ressaltar que neste caso foi necessário utilizar uma carga enzimática praticamente o dobro daquela utilizada no bagaço deslignificado, em relação ao teor de celulose presente em cada matriz. Segundo Carrillo et al. ${ }^{2}$ tanto o excesso de enzima quanto a presença de lignina limitam o processo de difusão da enzima no substrato e, consequentemente, a formação de glicose. Santos et al. ${ }^{18}$ observaram este fenômeno quando realizaram hidrólises do bagaço de cana-de-açúcar não deslignificado, com diferentes cargas enzimáticas. Devido a este fato, optou-se por utilizar uma carga enzimática menor na etapa de sacarificação e fermentação simultâneas.

\section{Fermentação dos hidrolisados enzimáticos}

Após as hidrólises dos materiais deslignificado ou não, foram realizadas fermentações destes hidrolisados pela levedura $S$. cerevisiae UFPEDA 1238. A Figura 3 apresenta os perfis de glicose, de celobiose e de xilose. Os perfis de consumo de glicose foram semelhantes nas fermentações com os dois tipos de hidrolisados. Durante as fermentações, a concentração de xilose em ambos hidrolisados permaneceu praticamente constante, uma vez que $S$. cerevisiae não consome xilose. ${ }^{19}$

A concentração de celobiose apresentou perfis diferentes dependendo do hidrolisado utilizado, isto é, na fermentação do hidrolisado do bagaço deslignificado, a concentração de celobiose aumentou nas primeiras $10 \mathrm{~h}$ e depois diminuiu, enquanto que na fermentação do hidrolisado do material não deslignificado a concentração de celobiose começou a diminuir a partir de $10 \mathrm{~h}$, indicando que, provavelmente, as enzimas adicionadas na hidrólise enzimática continuaram ativas durante a fermentação dos hidrolisados.

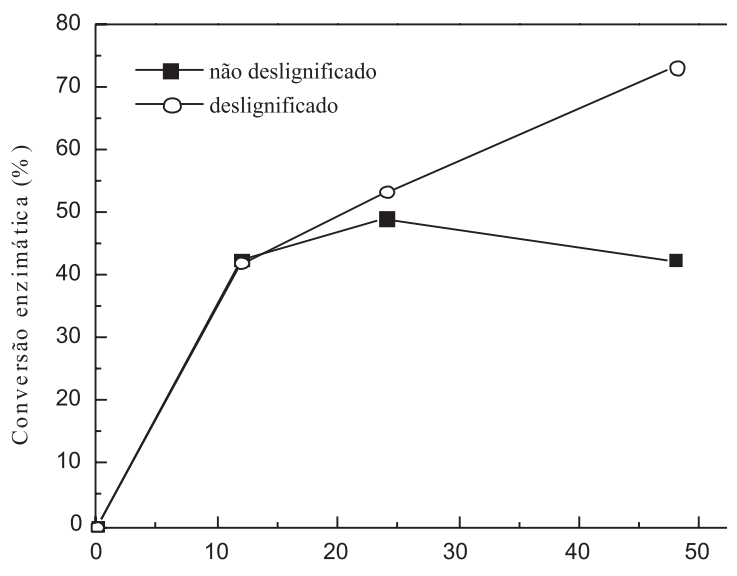

Figura 2. Conversão enzimática do bagaço com e sem deslignificação, durante as hidrólises enzimáticas

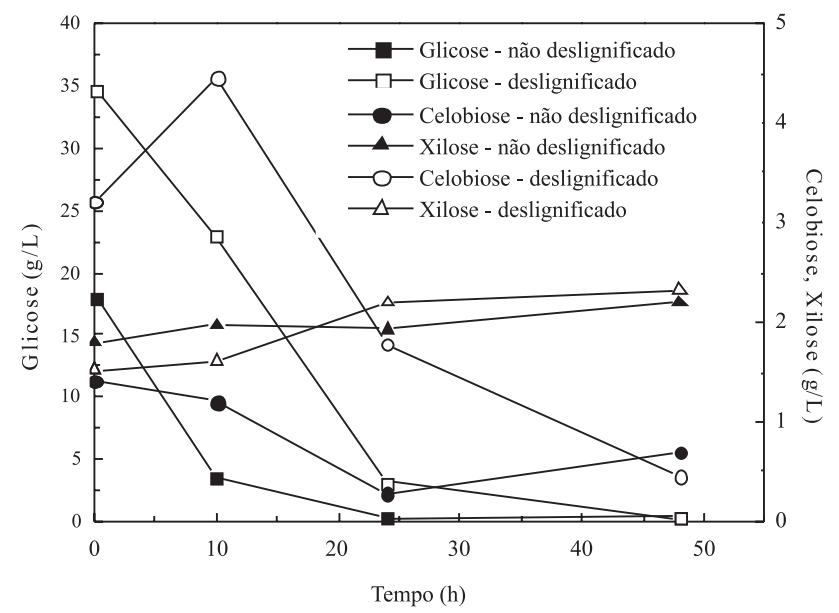

Figura 3. Concentração de glicose, de celobiose e de xilose durante as fermentações dos hidrolisados enzimáticos

A produção de etanol (Figura 4) foi maior na fermentação do hidrolisado do bagaço deslignificado, pois este continha maior concentração de glicose (Figura 1). Os rendimentos em etanol, obtidos em ambos os casos, foram: 0,30 e 0,35 g etanol/g glicose, para os hidrolisados dos bagaços não deslignificado e deslignificado, respectivamente. A produtividade volumétrica máxima também foi maior para a fermentação do hidrolisado do material deslignificado $(0,25$ $\mathrm{g} / \mathrm{L} \mathrm{h}$ ) do que para a fermentação do hidrolisado do material não deslignificado $(0,19 \mathrm{~g} / \mathrm{L} \mathrm{h})$.

\section{Fermentação e sacarificação simultâneas}

Nesta etapa do trabalho foram realizadas fermentações e sacarificações simultâneas, com e sem um período de pré-sacarificação. Foi utilizado apenas o bagaço deslignificado, uma vez que apresentou melhores resultados na etapa anterior.

No experimento 1, com pré-sacarificação e adicionando-se as enzimas em duas etapas (com 0 e 16 h), foi obtida uma conversão enzimática de $43 \%$, após 16 h. No experimento 2, com pré-sacarificação e adicionando-se as enzimas de uma só vez (no início da pré-sacarificação), foi obtida uma conversão enzimática de 49,0\%. Este resultado concorda com a ideia de que existe neste caso uma alta relação enzima-substrato presente em todo o período de présacarificação. A pré-sacarificação levou a uma rápida liquefação, e uma boa mistura foi alcançada após 16 h, quando o processo em 


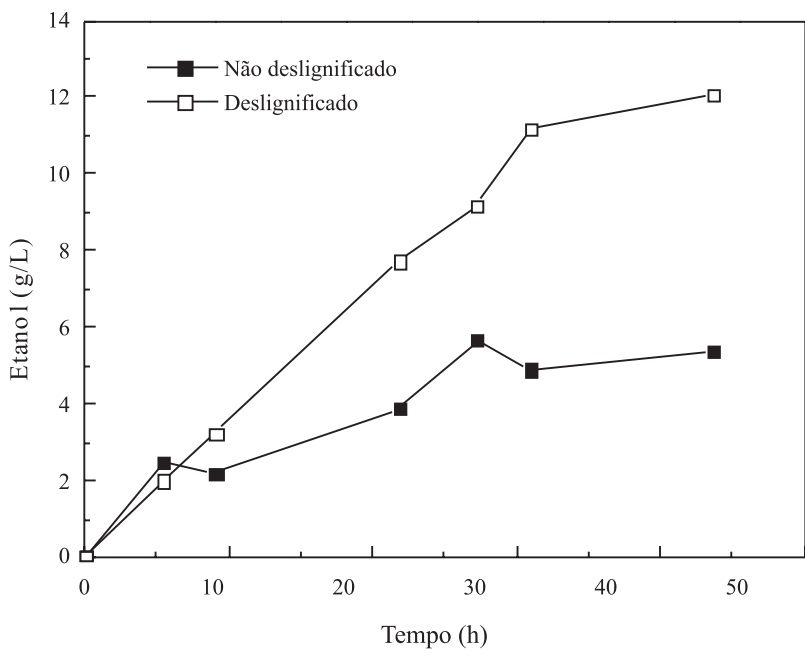

Figura 4. Concentração de etanol durante as fermentações dos hidrolisados enzimáticos

SSF foi iniciado. Isso também ocorreu no processo em SSF de outros materiais como trebol pré-tratado por oxidação úmida ${ }^{11}$ e bagaço de cana-de-açúcar pré-tratado por hidrólise ácida, ${ }^{20}$ quando se utilizaram etapas de pré-sacarificação de 6-12 h.

As Figuras 1Sa-c, do material suplementar, apresentam os perfis de glicose, de celobiose e de xilose, durante os processos em SSF. Como pode ser observado na Figura $1 \mathrm{Sa}$, a concentração de glicose nos experimentos 1 e 2 apresenta perfis semelhantes, sendo o perfil no experimento 2 apenas um pouco mais lento, uma vez que havia uma maior concentração inicial de glicose. Por outro lado, o experimento 3 apresentou um perfil completamente diferente dos outros dois experimentos. Isso ocorreu porque no experimento 3 não houve uma etapa de pré-sacarificação, daí este experimento começou com zero g/L de glicose. A concentração de glicose, neste caso, alcançou o valor máximo de cerca de $5 \mathrm{~g} / \mathrm{L}$, mas rapidamente foi consumida pela levedura, mantendo-se em valores muito baixos.

Com relação ao perfil de celobiose, a Figura $1 \mathrm{Sb}$ do material suplementar mostra que nos experimentos 1 e 2 este carboidrato também apresentou perfis semelhantes, iniciando com 1,5 g/L e diminuindo ao longo da fermentação e sacarificação simultâneas. No caso do experimento 3, a concentração de celobiose também foi zero no início, mas aumentou ao longo do processo até cerca de 0,6 $\mathrm{g} / \mathrm{L}$ e depois diminuiu.

As concentrações de xilose (Figura 1Sc, material suplementar) nos experimentos 1 e 2 mantiveram-se constantes como nas fermentações separadas dos hidrolisados, enquanto que no experimento 3 houve a conversão de hemicelulose em xilose, durante o processo em SSF, isto é, a preparação enzimática utilizada, provavelmente, contém enzimas xilanolíticas.

A produção de etanol apresentou o mesmo perfil para os experimentos 1 e 2 durante as primeiras $24 \mathrm{~h}$ de fermentação (Figura 5). Nas últimas $48 \mathrm{~h}$ a concentração de etanol no experimento 1 sofreu um pequeno aumento como resultado da disponibilidade de glicose produzida pela hidrólise da celulose durante a SSF, o que é uma consequência da adição das enzimas em duas etapas. No experimento 2 não foram observados incrementos adicionais da produção de etanol após 24 h, devido provavelmente à inativação térmica das enzimas, as quais foram adicionadas de uma única vez no início do processo. Para o experimento 3, a velocidade de formação de etanol foi menor e o perfil só se igualou ao apresentado nos experimentos 1 e 2, após 48 h. Daí, a produtividade volumétrica máxima para os experimentos $1(0,29 \mathrm{~g} / \mathrm{L} \mathrm{h})$ e $2(0,30 \mathrm{~g} / \mathrm{L} \mathrm{h})$, comparando com a do experimento 3
$(0,23)$, foi cerca de 1,3 vezes maior. Para o cálculo da produtividade volumétrica máxima para os experimentos 1 e 2 foi considerado o tempo de pré-sacarificação. Dessa forma, o tempo da produtividade volumétrica máxima foi de $40 \mathrm{~h}$ para os experimentos 1 e 2 e de 48 $\mathrm{h}$ para o experimento 3 .

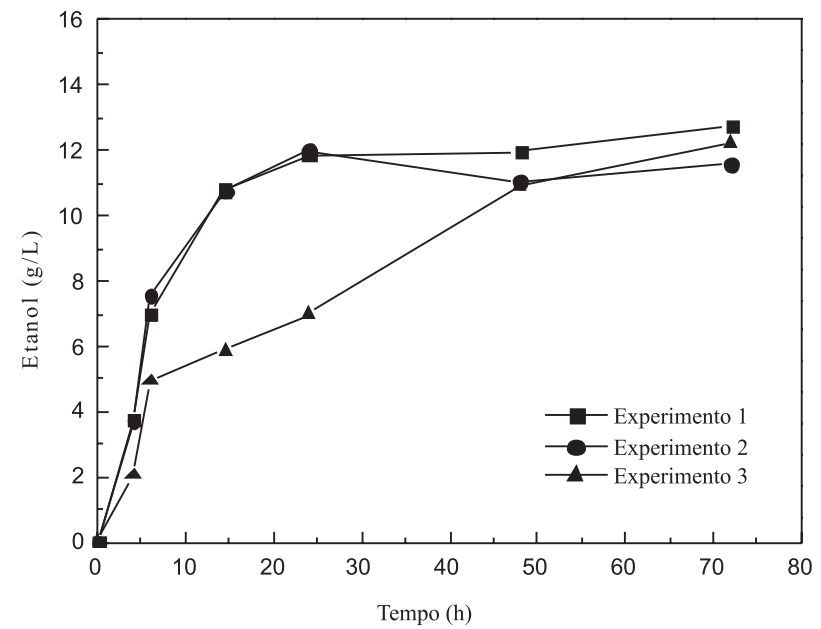

Figura 5. Concentração de etanol durante as sacarificações e fermentações simultâneas: experimento 1 (com adição das enzimas em duas etapas e $16 \mathrm{~h}$ de pré-sacarificação); experimento 2 (com adição das enzimas em uma única etapa e 16 h de pré-sacarificação); experimento 3 (sem pré-sacarificação)

A Figura 6 apresenta a conversão de celulose em etanol, para cada um dos três experimentos em SSF. Os perfis de conversão são bastante semelhantes apenas para os experimentos 1 e 2 . Foi observada uma conversão de cerca de $60 \%$ com $24 \mathrm{~h}$, nestes experimentos. Martin et al. ${ }^{11}$ encontraram uma conversão de cerca de $50 \%$ com $24 \mathrm{~h}$, no processo em SSF utilizando trebol.

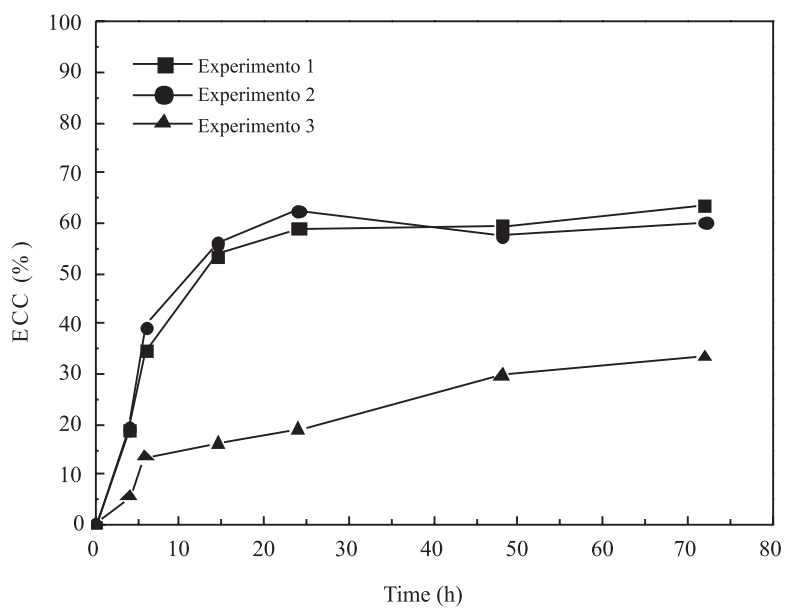

Figura 6. Conversão de celulose em etanol durante as sacarificações e fermentações simultâneas: experimento 1 (com adição das enzimas em duas etapas e 16 h de pré-sacarificação); experimento 2 (com adição das enzimas em uma única etapa e 16 h de pré-sacarificação); experimento 3 (sem pré-sacarificação)

Comparando os processos em SHF e em SSF, a Figura 7 apresenta as produtividades volumétricas máximas de etanol. Os maiores valores foram encontrados para os experimentos em SSF em que houve uma etapa de pré-sacarificação de $16 \mathrm{~h}$. No experimento 3 , a produtividade volumétrica máxima de etanol é comparável àquela da fermentação do hidrolisado obtido por hidrólise separada do bagaço deslignificado. 


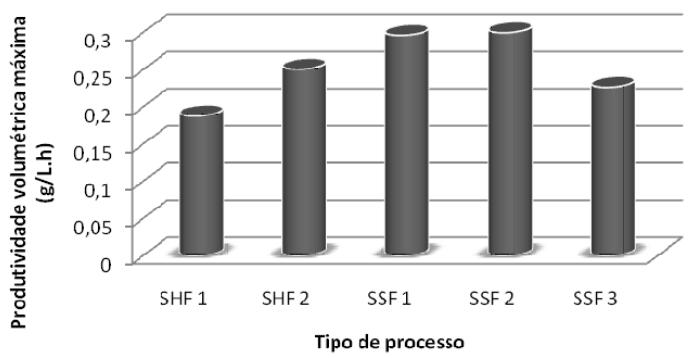

Figura 7. Comparação das produtividades volumétricas máximas dos processos em SHF (sacarificação e fermentação separadas) e SSF (sacarificação e fermentação simultâneas)

\section{CONCLUSÕES}

Nos processos em SSF, com pré-sacarificação, a conversão enzimática com $16 \mathrm{~h}$ foi muito próxima àquela obtida em período semelhante no processo em SHF, apesar de nos processos em SSF terem sido utilizadas quantidades menores das enzimas celulases e beta-glucosidase. Os processos em SSF com pré-sacarificação, adicionando-se as enzimas numa única etapa ou em duas etapas, mostraram-se promissores para a produção de bioetanol utilizando bagaço de cana-de-açúcar, pois foi observada uma redução no tempo total do processo, comparando-se com aqueles em SHF, que necessitaram de 48 h de hidrólise enzimática e mais 24 h de fermentação, totalizando $72 \mathrm{~h}$. Por outro lado, os processos em SSF necessitaram de apenas 16 h de pré-sacarificação e mais $24 \mathrm{~h}$ de fermentação e sacarificação simultâneas, dando um total de 40 h. O processo em SSF mostrou a possibilidade de, em experimentos futuros, se realizar batelada alimentada durante a sacarificação e fermentação simultâneas, para evitar tanto a inibição enzimática, quanto para aumentar a produção de etanol.

\section{MATERIAL SUPLEMENTAR}

O material suplementar contém as Figuras $1 \mathrm{Sa}$-c que apresentam os perfis de glicose, de celobiose e de xilose, durante os processos em SSF. Este material estará disponível gratuitamente em http:// quimicanova.sbq.org.br, na forma de arquivo PDF.

\section{AGRADECIMENTOS}

Ao CNPq (Processo 552732/2007-9) pelo auxílio financeiro e pela bolsa DTI (Desenvolvimento Tecnológico Industrial); à FACEPE (APQ 0213.3.06/08) pelo auxílio financeiro e ao Prof. Dr. G. J. de M. Rocha, da Escola de Engenharia de Lorena, pela doação do bagaço pré-tratado com vapor e das enzimas celulases e beta-glucosidase.

\section{REFERÊNCIAS}

1. Badhan, A. K.; Chada, B. S.; Kaur, J.; Saini, H. S.; Bhat, M., K.; Bioresour. Technol. 2007, 98, 504.

2. Carrillo, F.; Lis, M. J.; Colom, X.; Lopez-Mesas, M.; Valldeperas, J.; Process Biochem. 2005, 40, 3360.

3. Jan, H. D.; Chen, K. S.; World J. Microbiol. Biotechnol. 2003, 19, 263.

4. Lima, A. L. G.; Nascimento, R. P.; Bon, E. P. S.; Coelho, R. R. R.; Enzyme Microb. Technol. 2005, 37, 272.

5. Pandey, A.; Soccol, C. R.; J. Scient. Ind. Res. 2000, 59, 12.

6. Öhgren, K.; Bura, R.; Saddler, J.; Zacchi, G.; Bioresour. Technol. 2007, 98, 2503.

7. Tomás-Pejó, E.; Oliva, J., M.; Olsson, L.; Biotechnol. Bioeng. 2008, 100, 1122.

8. Olofsson, K.; Bertilsson, M.; Lidén, G.; Biotechnol. Biofuels 2008, 1, 7.

9. Palmqvist, E.; Hahn-Hägerdal, B.; Bioresour. Technol. 2000, 74, 17.

10. Philippidis, G. P.; Smith, T. K.; Wyman, C. E.; Biotechnol. Bioeng. 1993, $41,846$.

11. Martín C.; Thomsen, M., H.; Hauggaard-Nielsen, H.; Thomsen, A. B.; Bioresour. Technol. 2008, 99, 8777.

12. Lima, U. A.; Basso, L. C.; Amorim, H. V. Em Biotecnologia Industrial; Lima, U. A.; Aquarone, E.; Borzani, W.; Schmidell, W., eds, Edgard Blücher Ltda: São Paulo, 2001, vol. III, cap 1.

13. Adsul, M. G.; Ghuleb, J. E.; Singhb, R.; Shaikhb, H.; Carbohydr. Polym. 2005, 57, 67.

14. Santos, J. R. A.; Gouveia, E. R.; Rev. Bras. Prod. Agroind. 2009, 11, 27.

15. Gouveia, E. R.; Nascimento, R. T.; Souto-Maior, A. M.; Rocha, G. J. M.; Quim. Nova 2009, 32, 1500.

16. Laser, M.; Schulman, D.; Allen, S. G.; Lichwa, J.; Antal, Jr. M. J.; Lynd, L. R.; Bioresour. Technol. 2002, 81, 33.

17. Chen, M.; Xia, L.; Xue, P.; Int. Biodeter. Biodegr. 2007, 59, 85.

18. Santos, J. R. A.; Pinheiro, I. O.; Souto-Maior, A. M.; Gouveia, E. R.; Anais do XVII Congresso Brasileiro de Engenharia Química, Recife, Brasil, 2008.

19. Olsson, L.; Hahn-Hagerdal, B.; Enzyme Microb. Technol. 1996, 18, 312.

20. Martín, C.; Moss, C.; Fernández, T.; Martínez, A.; Anais do X Congresso Internacional sobre Açúcar e Derivados da Cana, La Habana, Cuba, 2008. 


\section{COMPARAÇÃO ENTRE PROCESSOS EM SHF E EM SSF DE BAGAÇO DE CANA-DE-AÇÚCAR PARA A PRODUÇÃO DE ETANOL POR Saccharomyces cerevisiae}

Julliana Ribeiro Alves dos Santos, Ana Maria Souto-Maior e Ester Ribeiro Gouveia*

Departamento de Antibióticos, Universidade Federal de Pernambuco, 50670-901 Recife - PE, Brasil

Carlos Martín

Departamento de Química e Ingeniería Química, Universidad de Matanzas, 44740 Matanzas, Cuba

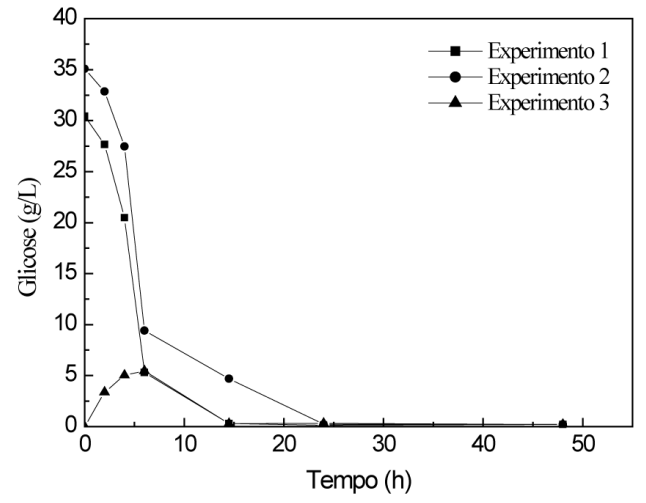

(a)

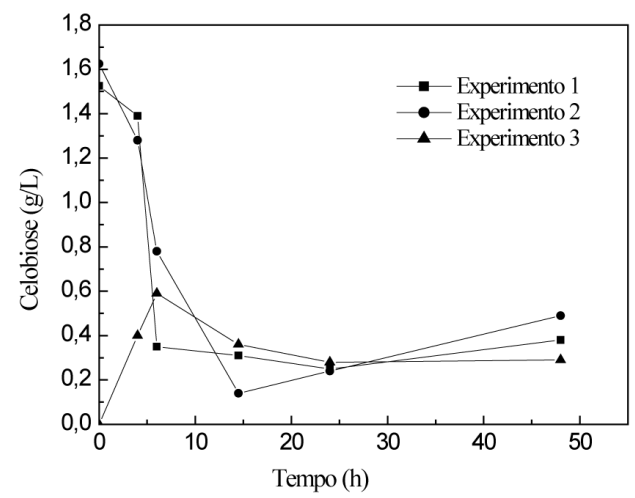

(b)

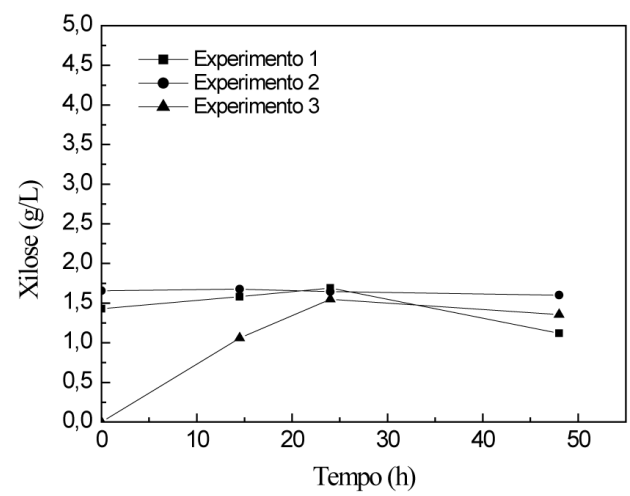

(c)

Figura 1S. Concentração de glicose (a), celobiose (b) e xilose (c) durante as sacarificações e fermentações simultâneas: experimento 1 (com adição das enzimas em duas etapas e $16 \mathrm{~h}$ de pré-sacarificação); experimento 2 (com adição das enzimas em uma única etapa e 16 h de pré-sacarificação); experimento 3 (sem pré-sacarificação) 